The International Journal Of Engineering And Science (IJES)

|| Volume || 6 || Issue || 2 || Pages || PP 49-58 || 2017 ||

ISSN (e): $2319-1813 \operatorname{ISSN}(\mathrm{p}): 2319-1805$

\title{
Turbofan Engine Modelling and Control Design using Linear Quadratic Regulator (LQR)
}

\author{
Jackson Lutambo \& Jiqiang Wang \\ College of Energy and Power Engineering, Nanjing University of Aeronautics and Astronautics, Nanjing, \\ 210016 China
}

\begin{abstract}
There are many applications in which gas turbine engine is used today, including aircraft propulsion for both commercial and military purposes, and power generation and in all these Control systems technology has played a fundamental role in enhancing performance. Modelling plays a significant role in the development of the entire engine system performance. This paper investigated Linear Quadratic Regulator (LQR) model-based control method to obtain estimates of performance parameters. The main control variable selected is the fuel flow to control the rotational speed of high-pressure spool speed of the turbofan engine. Firstly a suitable mathematical model of the engine is developed in MATLAB Simulink environment with both the intercomponent volume and the constant mass flow methods used. Equations of the mass flow rate and the torque balance are incorporated in the steady state and dynamic state of the thermodynamic engine model. This represents the engine model by a set of first-order differential and algebraic equations and a linearized model is extracted for the analysis and design of a controller by LQR. It is demonstrated that LQR based controllers can perform better than conventional PID controllers. The settling time, rise time and maximum overshoot for $L Q R$ based controller are all less than those for PID based controller. The input also changes more accurately for LQR than the PID controller compared.
\end{abstract}

Keywords: Control System Design, Linear Quadratic Regulator (LQR), Modelling and Simulation, Transient Performance, Turbofan Engine.

Date of Submission: 26 January 2017

Date of Accepted: 28 February 2017

\section{NOMENCLATURE}

$A=$ state coefficient matrix

$\mathrm{B}=$ input coefficient matrix

$\mathrm{Cp}=$ specific heat capacity

$\mathrm{HV}=$ Heating value of fuel

$\mathrm{J}=\mathrm{LQR}$ performance measure

$\mathrm{J}=$ moment of inertia

$\mathrm{K}=\mathrm{LQR}$ gain matrix

$\mathrm{LQR}=$ linear quadratic regulator

$\dot{m}=$ mass flow rate

$\mathrm{N}=$ rotational speed

$\mathrm{P}=$ pressure

$Q=$ matrix of error weights

$\mathrm{R}=$ control weights

$\mathrm{T}=$ temperature

$\mathrm{U}=$ input matrix

$\mathrm{X}=$ system state matrix

$\theta=$ temperature ratio

$\sigma=$ pressure ratio

$\mathrm{W}=$ work

$\gamma=$ ratio of specific heats

$\eta=$ efficiency 


\section{INTRODUCTION}

The turbofan engine has found its use mostly in aircraft propulsion. It operates by absorbing the excess energy from the high-pressure turbine to drive a fan and low-pressure compressor located upstream of the main compressor section [1]. In aircraft propulsion, it performs a number of key functions, firstly it provides the propulsive energy to propel the aircraft throughout its route while achieving appropriate performance and efficiency. Secondly, it provides the prime source of energy for the on-board systems by generating electrical power and driving other components responsible for producing hydraulic and pneumatic power. Finally, it provides the air to create a habitable environment for the crew, passengers, and avionics equipment. It also costs a substantial amount of investment and its incorporation into the aircraft affects both airframe and systems in terms of safety, reliability, and cost of ownership [2].

The goal of any engine control system is to enable the engine to realize high accuracy, reliability, performance and efficiency in all exploitation conditions [3]. The modern turbofan is highly fuel efficient and control technology has contributed significantly to the attainment of this effect. In recent years great research work has been done in the field of modelling and simulating of gas turbines. Making models of gas turbines and their related control systems have been a useful technical and cost-saving strategy for performance enhancement and testing before manufacturing [4].

At first, a suitable mathematical model for the turbofan engine is built in Matlab/Simulink software [5]. After building the model it is desirable to extract a linearized model to be used for analysis and design. Most of the analytical techniques that are commonly used for analysis and design of control systems can only be applied to linear models and this is accomplished within Matlab/Simulink. The idea of using fuel flow rate to control thrust as in the earlier hydromechanical systems is still the strategy in many gas turbine engines today. Other control signals are often used for limiting the engine from exceeding its operating range [6]. In this model, the input signal is the fuel flow and the output signal is the high-pressure compressor rotational speed. The more accurate control of engine thrust which is the primary control objective of the gas turbine engine can be obtained through the control of compressor speed [7]. The desired performance requirements are to obtain faster response without any overshoot. In this paper, controller design has been carried out for speed control of twin spool turbofan engine by LQR control method and fuel flow rate was used as the input. The objective of the LQR control design is to calculate the optimal feedback gain matrix $\mathrm{K}$ such that the feedback law

$u=-K x$ :

Minimizes the cost function

$J=\int_{0}^{t}\left(x^{T} Q x+u^{T} R u\right):$

With the constraint equation being

$\dot{x}=A x+B u$ :

After obtaining the A and B matrices in Simulink the main task is selecting Q and R matrices subject to the further constraints that $\mathrm{Q}$ be symmetric positive semi-definite and $\mathrm{R}$ be symmetric and positive definite.

\section{MODELLING OF TURBOFAN ENGINE.}

Many software packages are now available for modelling systems and a considerable research work has been carried out in the field of modelling and simulation of turbine engines with the view of understanding the subject well before building physical models. This great work has been carried out because the need for and use of gas turbines have become more apparent in the modern industry. Modelling of turbine engines and control systems has been a useful technical and cost-saving strategy for performance optimization of the equipment before making and testing the final product [7]. Gas turbine models and simulators can be used for off-design performance prediction, performance deterioration and evaluation of emissions, turbine creep life usage and the engine control systems [8]. Mathematical modelling is considered as a general approach to system modelling and uses mathematical language to describe and predict the behaviour of a system.

A mathematical model of a gas turbine engine consists of mathematical equations, maps, and tables which describe the thermodynamic relationships of various variables in the engine. The model developed here consists of individual components such as inlet, fan, compressors, combustor, turbines and nozzle [9]. The components require a number of input variables to generate the output variables. The schematic representation of an axial flow, unmixed-flow, twin-spool and high-by-pass ratio turbofan engine typical of the one developed in this paper is shown in fig 1 . The model is built in the Matlab simulation environment and its Simulink toolbox with inter-component volume and constant mass flow assumed. The complete model of turbofan engine components with the control volumes and torque balance on the rotating group developed in Simulink is shown 
in fig 2. The thermodynamic equations of the components and the set of static and dynamic equations were used in this model.

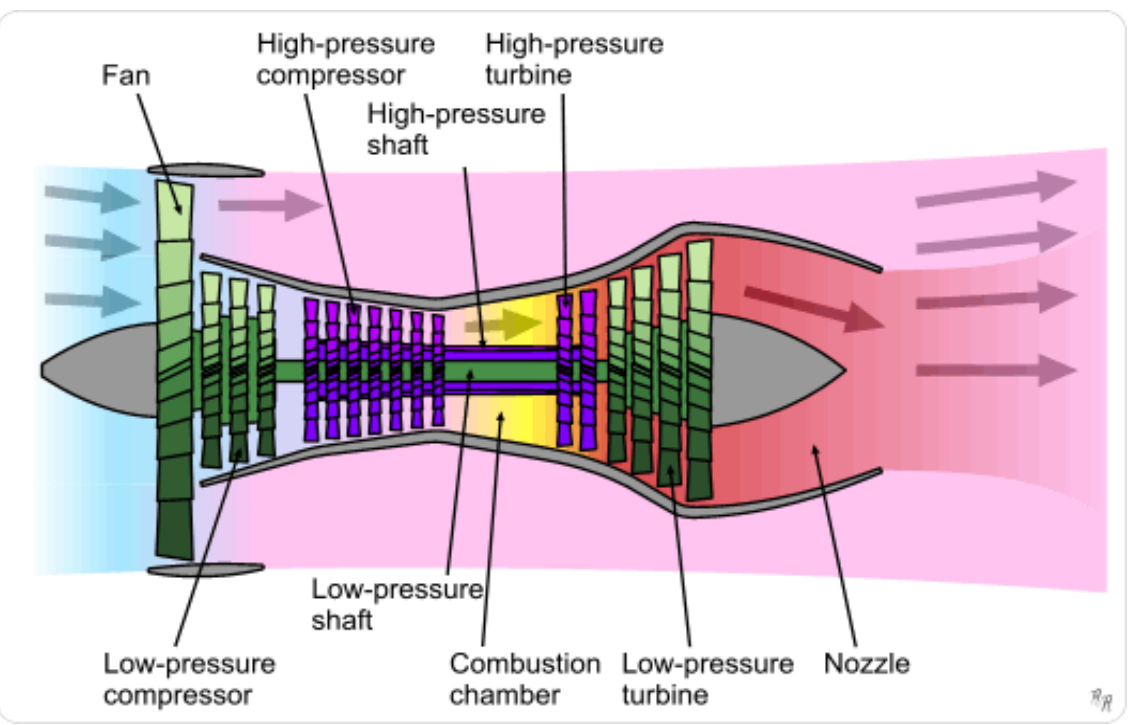

Figure 1 Turbofan Unmixed Flow Engine

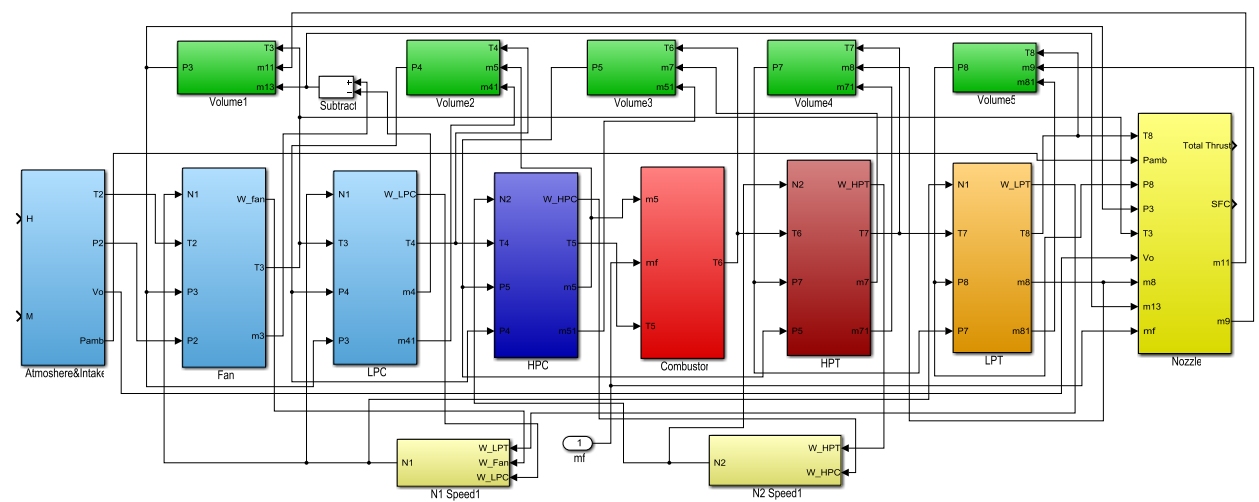

Figure 2 Simulink Model of a Turbofan Engine

\subsection{Compressor}

The task of the compressor is to increase the pressure of air required by the engine. The axial flow compressor is considered here i.e. one in which the flow enters in an axial direction parallel to the axis of rotation. The overall performance maps are used to represent the steady performance of the compressor which is good enough for real-time simulation. The typical performance maps and the governing equations are similar for the fan, low-pressure compressor, and high-pressure compressor. The map values of airflow and efficiency are computed from functions of pressure ratio and corrected speed using 2-D lookup tables were through interpolation the mass flow and efficiency are determined [10]. The following equations are used to calculate various parameters together with the map.

Temperature ratio,

$\theta=T_{t} / T_{\text {std }}$ :

Pressure ratio,

$\sigma=P_{t} / P_{s t d}$ :

Normalized speed

$N_{\text {corr }}=N /\left(N_{\text {des }} * \sqrt{\theta}\right)$ :

Mass flow rate,

$\dot{m}_{3}=\dot{m}_{3 \text { corr }} * \sigma / \sqrt{\theta}$ :

Temperature, 


$$
T_{3}=T_{2} *\left\{1+1 / \eta_{\text {fan }} *\left[\left(\pi_{f a n}\right)^{((\gamma-1) / \gamma)}-1\right]\right\}:
$$

Work,

$W_{f a n}=\dot{m}_{3} * C_{p} *\left(T_{3}-T_{2}\right)$ :

\subsection{Combustion Chamber}

The combustion chamber provides an environment where fuel/air mixture burns and release the hot gases with its energy to the turbine and then the nozzle sections of the engine. The combustion process in the model is simplified and assumed to be instantaneous after the fuel injection but the actual process is a complex one.

Theoretically, in the combustion process the inlet and outlet pressures of the combustion chamber are assumed to be the same but in practice, the pressure drops in the combustion chamber. Because of this pressure drop, the gases in the combustion chamber can flow rearwards. Temperature is given by the Energy balance equation

$T_{6}=\frac{\eta_{\text {comb-eff }} * H V * \dot{m}_{f}+\dot{m}_{a i r} * C_{p} * T_{5}}{\left(\dot{m}_{a i r}+\dot{m}_{f}\right) * C_{p-g a s}}:$

\subsection{Turbine}

The Turbine is used to extract sufficient energy from the hot gases of the combustor to drive the compressor and other components attached, like pumps and generators. In this model the turbine is assumed to be an axial flow turbine and both low and high-pressure turbines are modelled with same equations [11]. But while modelling the engine in Simulink, the turbine is modelled as a single block by stacking the stages of the turbine into a single block. Dynamic behavior of all the individual stages is also stacked into a single block with only the inlet and final exit conditions of the turbine. From the values of the corrected mass flow rate and the turbine efficiency, the actual mass flow rate and the temperature can be calculated from the expressions,

Actual mass flow rate,

$\dot{m}_{7}=\frac{\dot{m}_{6-\text { corr }} * \delta}{\sqrt{\theta}}$ :

Temperature,

$T_{7}=T_{6} *\left\{1+\eta_{h p t} *\left[1-\left(\pi_{h p t}\right)^{\frac{\gamma_{g a s}-1}{\gamma_{g a s}}}\right]\right\}:$

Work of the turbine,

$W_{h p t}=\dot{m}_{7} * C_{p-g a s} *\left(T_{6}-T_{7}\right)$ :

\subsection{Nozzles}

A convergent nozzle is considered in modelling the engine. The partially expanded gas coming from the turbine is accelerated to a high velocity in the nozzle and expand to the ambient pressure.

The nozzle is to be checked first to define whether it is choked or not. Thus the critical pressure is calculated from the relationship:

$$
P_{c}=P_{8} *\left(\frac{2}{\gamma+1}\right)^{\frac{\gamma}{\gamma-1}}:
$$

Thrust can be calculated from

$$
\begin{aligned}
F & =\dot{m} *\left(V_{9}-V_{0}\right)+A_{n o z z l e} *\left(P_{9}-P_{a m b}\right): \\
V_{9} & =\sqrt{2 * C_{p} *\left(T_{8}-T_{9}\right)}: \\
T_{9} & =T_{8} *(2 /(\gamma+1)): \\
P_{9} & =P_{a m b}:
\end{aligned}
$$

For unchoked nozzle and

$V_{9}=\sqrt{\gamma * R * T}$ : 


$$
\begin{aligned}
& T_{9}=T_{8} *\left(P_{9} / P_{8}\right)^{\frac{\gamma}{\gamma-1}}: \\
& P_{9}=P_{\text {critical }}:
\end{aligned}
$$

For choked nozzle

\subsection{Volume Dynamics}

Inter-component volume dynamics between various components to account for incoming and outgoing mass flows is considered at engine locations where the dynamics are important or required to avoid the need for an iterative solution. The storage of energy and mass take place in these volumes and the dynamic pressure can be calculated by the ideal gas law integration

$$
P=\int \frac{\left(\dot{m}_{\text {in }}-\dot{m}_{\text {out }}\right)}{V} d t \text { : }
$$

\subsection{Shaft Dynamics}

At steady state, the operating points of the compressor must match with that of the turbine. Any mismatch between the compressor and turbine will produce unbalanced torque. Therefore the change of torque is a function of the energy difference between the turbine and the compressor and is given by

$$
\dot{N}=\left\lceil\frac{30}{\pi}\right\rceil^{2} * \frac{1}{J N}\left[P W_{t}-P W_{c}\right]:
$$

\section{CONTROLLER DESIGN BY LINEAR QUADRATIC REGULATOR}

The objective of the LQR controller is to select the gain K equation (1) that minimizes the performance index ( $\mathrm{J}$ ) equation (2) [13]. A controller is designed to keep a stationary system within an acceptable deviation from a reference condition using an acceptable level of control. The controller moves the system from an initial state $\mathrm{x}(\mathrm{t} 0)$ to a terminal state using input control $\mathrm{u}(\mathrm{t})$ without exceeding acceptable levels of the state. The linear quadratic control refers to a body of techniques using optimal control developed for control system design. The plant is assumed to be a linear system in state space form and the cost function is a quadratic function of the plant states and control input.

The cost function $\mathbf{J}$ represents the weighted sum of energy of the state and control. The weighting matrices Q and R control the characteristics of the system. By weighting R more than Q the control energy is penalized heavily translating into smaller actuators, motors, and gains required for implementing the control law. By weighting $\mathrm{Q}$ much larger than $\mathrm{R}$ the state is similarly affected resulting in a damped system, which avoids larger fluctuations or overshoots in system states. An appropriate choice of $\mathrm{Q}$ and $\mathrm{R}$ must be made to obtain acceptable levels of $x(\operatorname{tr}), x(t)$ and $u(t)$ [14]. The system can be represented in state space as shown in fig 3

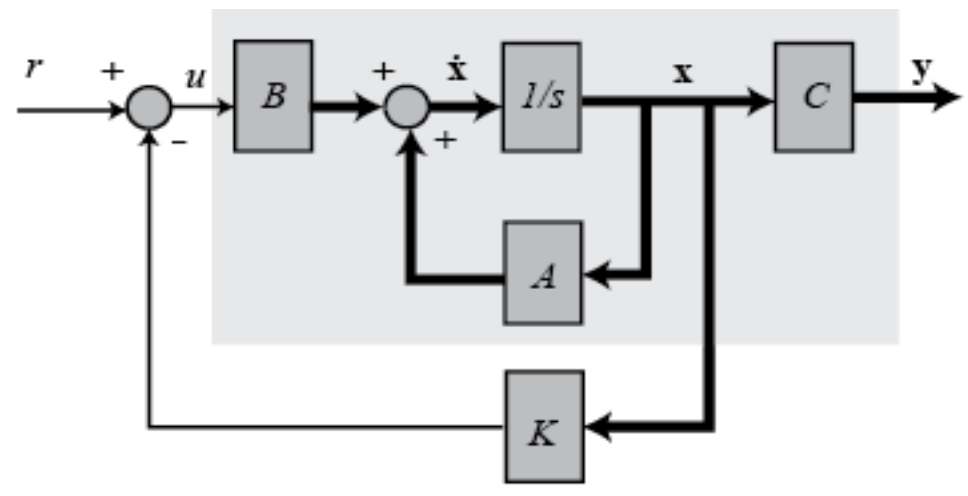

Figure 3 State-Space Representation of the System

To solve using LQR controller design the following assumptions are made:

1 the entire state vector $\mathrm{x}(\mathrm{t})$ is available for feedback.

2 the system is both controllable and observable.

The design steps are as follows:

Select design parameter matrices $\mathrm{Q}$ and $\mathrm{R}$

Solve the algebraic Riccati equation for $\mathrm{P}$ 
$A^{T} P(t)+P(t) A+Q-P(t) B R^{-1} B^{T} P=0:$

Determine the optimal state feedback gain $\mathrm{K}$

$K=R^{-1} * B^{T} * P$ :

$u=-K * x$ :

The system is described by

$\left\{\begin{array}{l}\dot{x}=A x+B u \\ y=C x+D u\end{array}\right\}$ :

The performance index is defined by

$$
J=\int_{0}^{\infty}\left(x^{T} Q x+u^{T} R u\right) d t:
$$

Where Q: nxn semi-positive definite matrix

$\mathrm{R}$ : mxm positive definite matrix

\section{IV.SIMULATIONS AND RESULTS}

After the model is built in Simulink as described in section 2 above, first there is a need to extract the linearized state space model from the entire system. In order to extract we need to define the input which is fuel flow in this case and the output signal which is high-speed spool speed of the model. At the Matlab prompt using the command linmod.m the linearized model is obtained from the systems of ordinary differential equations(ODEs) containing the matrices A,B,C and D. The equivalent transfer function obtained is

$\mathrm{X}(\mathrm{s})=$

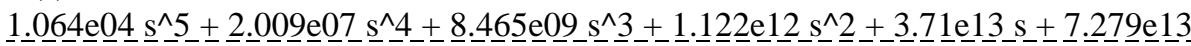

$\mathrm{s}^{\wedge} 6+1807 \mathrm{~s}^{\wedge} 5+7.462 \mathrm{e} 05 \mathrm{~s}^{\wedge} 4+9.662 \mathrm{e} 07 \mathrm{~s}^{\wedge} 3+3.049 \mathrm{e} 09 \mathrm{~s}^{\wedge} 2+1.19 \mathrm{e} 10 \mathrm{~s}+1.29 \mathrm{e} 10$

Initially, the system is simulated to obtain the open loop response and fig 7 shows the simulation of high-speed spool speed in open loop and fig 8 shows the associated bode plot. As can be seen from the figure the system has slow rise time ( 0.894 seconds), settling time ( 1.53 seconds) and has no overshoot so it needs to be improved by adding a controller.

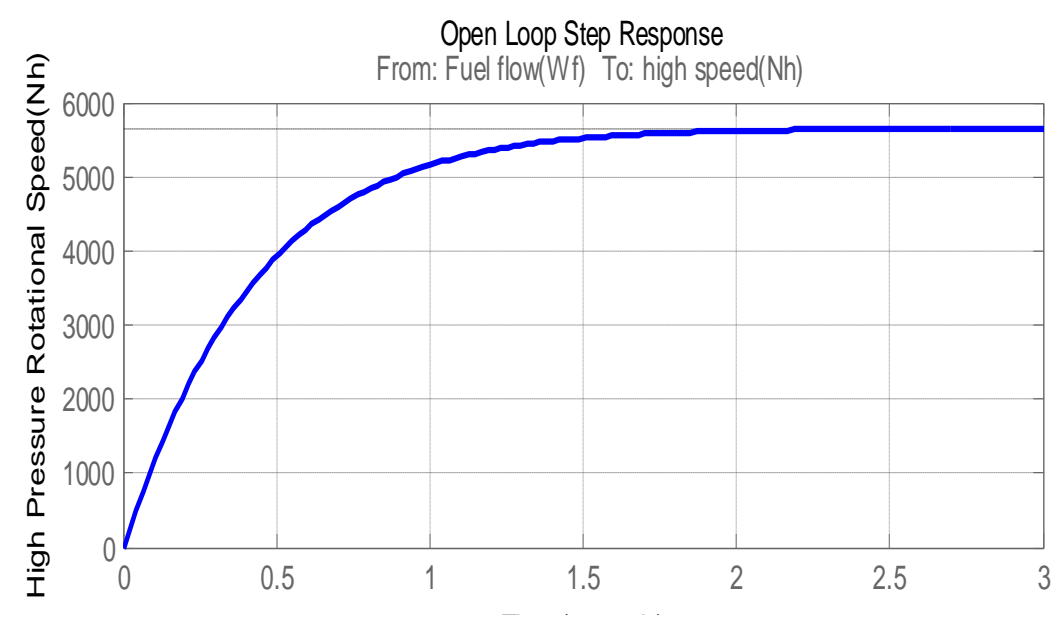

Figure7 Open Loop Response 


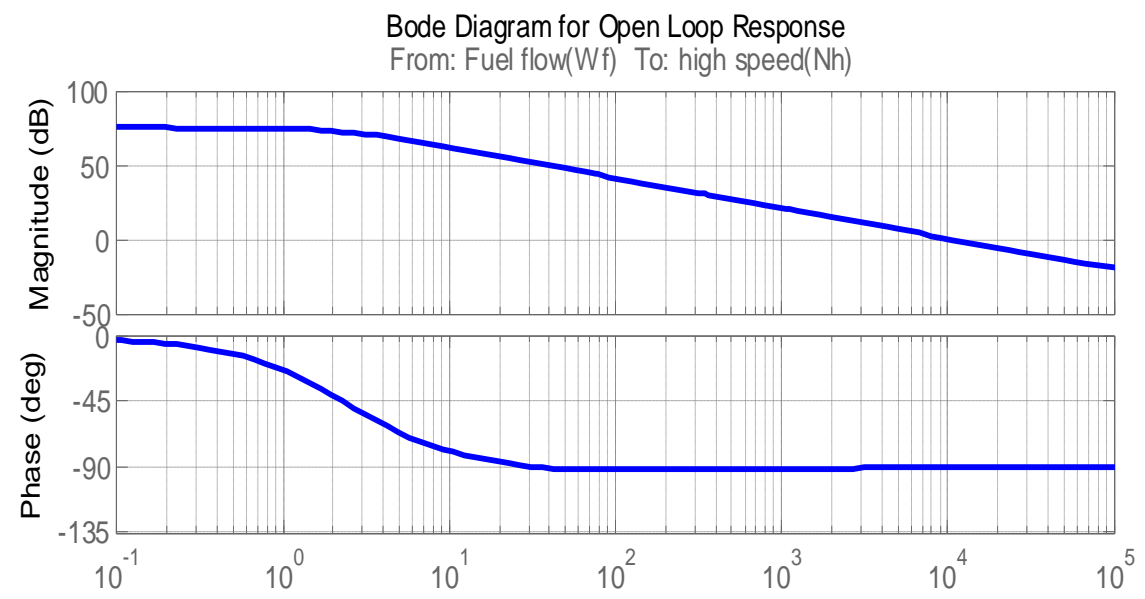

Figure 8 Bode Diagram for Open Loop Response without the Controller.

\subsection{Proportional Integral Controller}

The PI controller was implemented and was found to give good enough response. After several trials the gains $\mathrm{Kp}=0.3$ and $\mathrm{Ki}=6.3101$ gave the desired response. The settling time was found to be 0.000103 seconds, rise time was 0.000643 seconds and $1 \%$ overshoot and fig 9 and fig 10 show the step response and bode plot respectively after simulation.

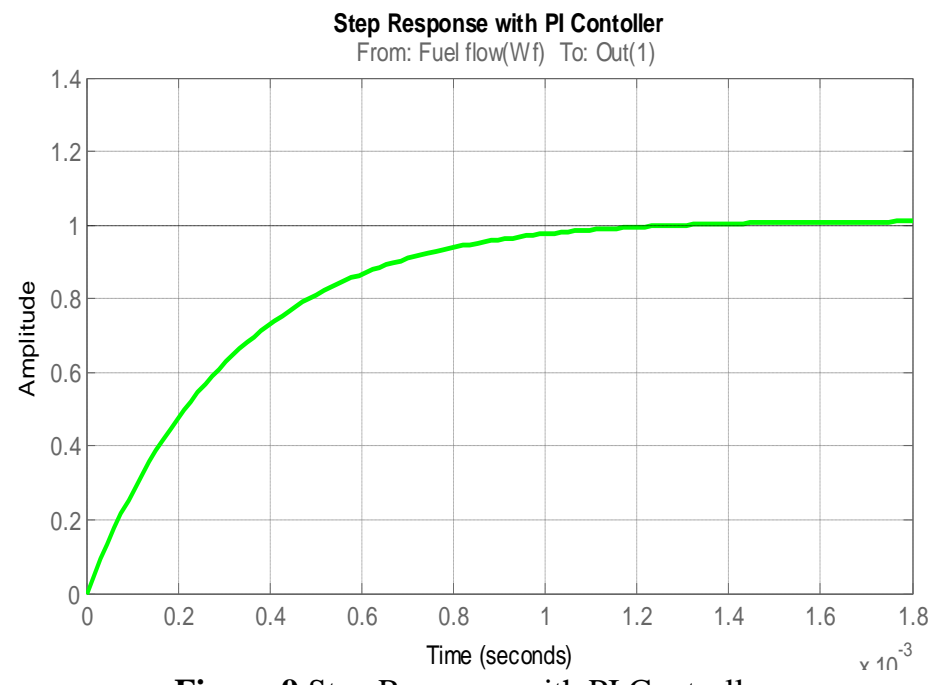

Figure 9 Step Response with PI Controller

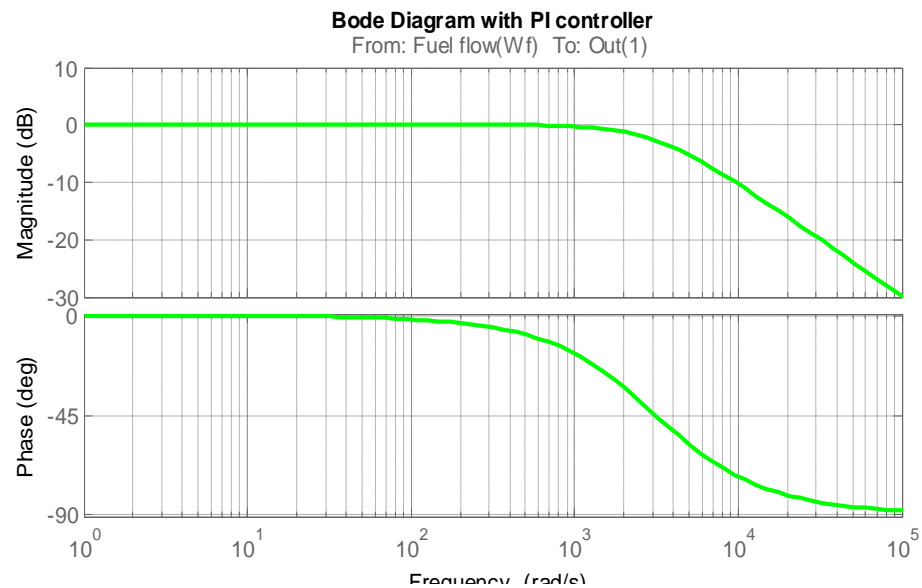

Figure 10 Bode Diagram with PI Controller 
When designing LQR controller, the function in Matlab can be used to determine the value of the gain vector $\mathrm{K}$ to determine the feedback control law. This is done by initially choosing parameter values using Anderson approximation which is given by

$$
Q=C^{T} * C:
$$

and $\mathrm{R}=1$.

$$
Q=\left\{\begin{array}{llllll}
1 & 0 & 0 & 0 & 0 & 0 \\
0 & 0 & 0 & 0 & 0 & 0 \\
0 & 0 & 0 & 0 & 0 & 0 \\
0 & 0 & 0 & 0 & 0 & 0 \\
0 & 0 & 0 & 0 & 0 & 0 \\
0 & 0 & 0 & 0 & 0 & 0
\end{array}\right\}
$$

Using the $\mathrm{Q}$ obtained and $\mathrm{R}=1$ the feedback gain is found to be $\mathrm{K}=\left[\begin{array}{llllll}0.9997 & 0.0000 & 0.0000 & 0.0000 & 0.0000 & 0.0000\end{array}\right]$

The symmetric matrix $\mathrm{P}$ is found to be

And the system poles were

$$
P=\left\{\begin{array}{cccccc}
0.00009332 & 0 & 0 & 0 & 0 & 0 \\
0 & 0 & 0 & 0 & 0 & 0 \\
0 & 0 & 0 & 0 & 0 & 0 \\
0 & 0 & 0 & 0 & 0 & 0 \\
0 & 0 & 0 & 0 & 0 & 0 \\
0 & 0 & 0 & 0 & 0 & 0
\end{array}\right\}
$$

$-10630,-1359,-316,-167,-46,-2$

The step response of the closed loop system with LQR controller is as shown on fig 11 and the associated bode plot in fig 12. From the graph and the poles of the system, the system behaves as if it were first order system because the poles are far apart. The pole at -2 dominates the transient response behaviour as it is the term that decays slowly. The poles of large negative values can be ignored as their transient response behavior [15] is assumed to be too fast to contribute to the system dynamics as this can be seen from the figure.

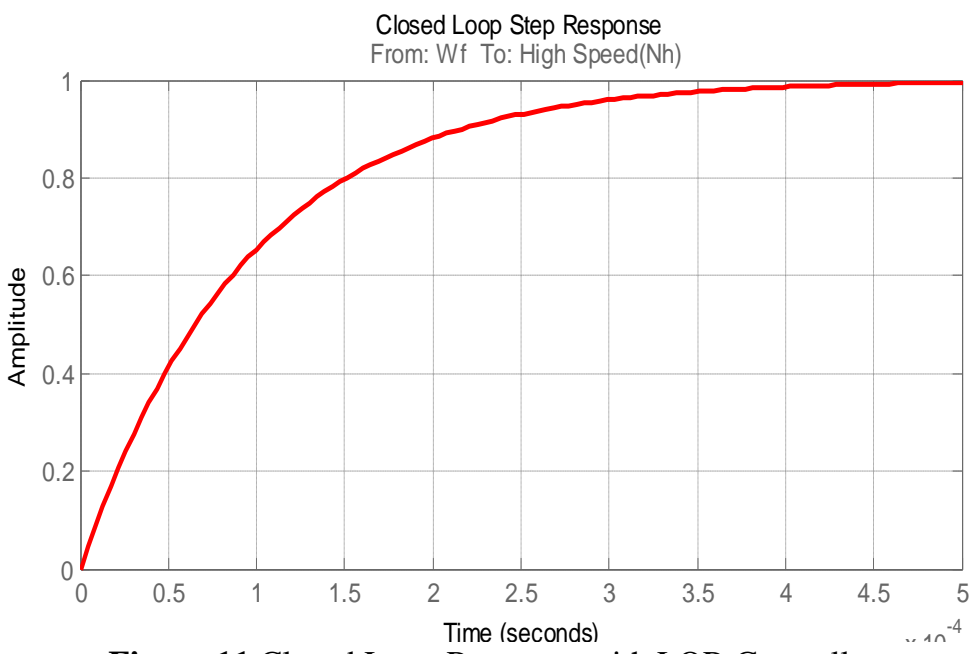

Figure 11 Closed Loop Response with LQR Controller 


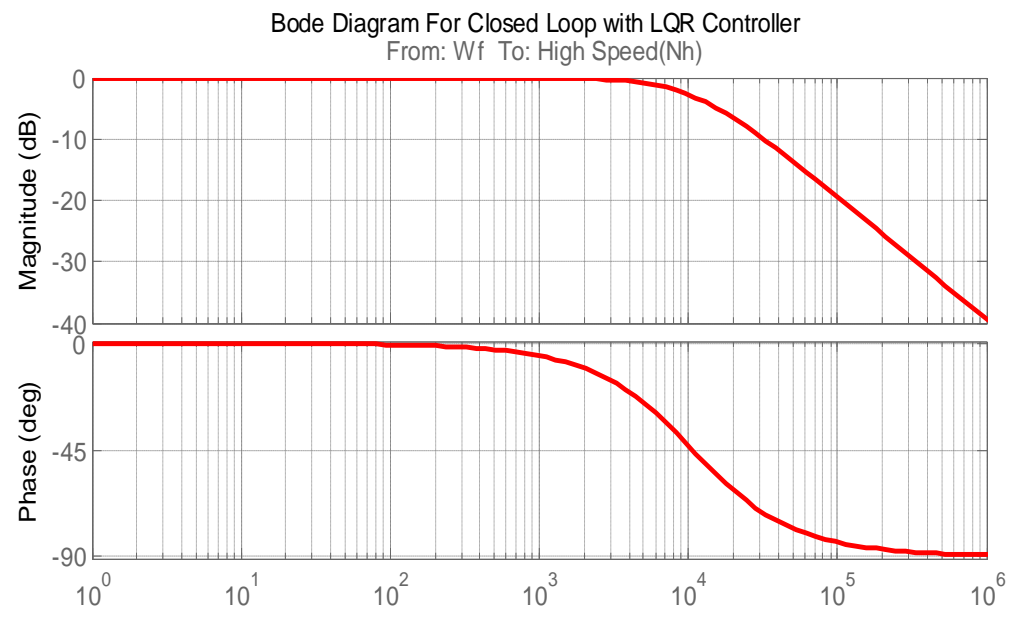

Figure 12 Bode Diagram for Closed Lö̀ with LQR Controller

As shown from fig 11 the response is much faster and it meets the specifications. The settling time is now 0.00036 seconds, rise time is 0.000206 seconds and there is no overshoot. Table 1 below shows the different responses of the system in open loop, with PI controller and LQR controller. The LQR controller performance was better than the PI controller as it shows faster responses, in terms of settling time, rise time and overshoot. Therefore LQR controller better meets the requirements of design specifications than then PI controller in this case.

Table 1 Comparison between PI and LQR

\begin{tabular}{|l|l|l|l|}
\hline Characteristic & Open Loop & PI & LQR \\
\hline Settling Time & $1.53 \mathrm{sec}$ & $0.00103 \mathrm{sec}$ & $0.000365 \mathrm{sec}$ \\
\hline Rise Time & $0.894 \mathrm{sec}$ & $0.000643 \mathrm{sec}$ & $0.000206 \mathrm{sec}$ \\
\hline Steady State & 1 & 1 & 1 \\
\hline Overshoot & $0.0198 \%$ & $1 \%$ & $0 \%$ \\
\hline
\end{tabular}

\section{CONCLUSION}

In this paper, the LQR control technique was used to design a controller for the turbofan engine. The model was first built in Matlab Simulink and a linearized state space representation was extracted to be used for analysis and design of the controller. Results show that the Linear Quadratic Regulator is capable of stabilizing the system and produce system responses with smaller rise time, settling time, and no overshoot as compared to the PI controller. The LQR controller is observed to have performed satisfactorily for the SISO case considered in this paper. In case where there are too many variables and inputs LQR method may be a viable approach were classical design methods are limited.

\section{ACKNOWLEDGEMENT}

I would like to thank the university and staff of Nanjing University of Aeronautics and Astronautics for funding to make this paper published.

\section{REFERENCE}

[1] H. Klause, Jet Engines, Fundamentals of theory, Design and operation, Motorbooks International Publishers and wholesalers, Osceola, USA 2003.

[2] Bernie M, Roy L. Gas Turbine Propulsion Systems. A. John Wiley \& Sons, Ltd. West Sussex, UK, 2011.

[3] J. Sun, V. Vasilyev, Ilyasov, Advanced Multivariable Control Systems of Aeroengines, buaa press. Beijing, China, 2005.

[4] E. Tsoutsanis et al. Dynamic Performance Simulation of an Aeroderivative Gas Turbine Using The Matlab Simulink Environment, Proceedings of the ASME International Mechanical Engineering Congress \& Exposition IMECE November, 2013 San Diego, California, USA.

[5] A. M. Y. Razak, Industrial Gas Turbines: Performance and Operability, Woodhead Publishing Limited, Cambridge, England, 2007, First Ed.

[6] H. Melker, Multivariable Control Design for a Jet Engine, Proceedings of $13^{\text {th }}$ Triennial World Congress, San Francisco, USA 1996. Volvo Aero Corporation, Sweden.

[7] A. J. Sobey and A. M. Suggs, Control of aircraft and Missile Power Plants, John Willey and Sons inc. New York, 1983.

[8] M. Bazazzadel, H. Badihi and A. Shahriari, Gas Turbine Engine Control Design Using Fuzzy Logic and Neural Networks, International Journal of Aerospace Engineering, 2011, Volume 2011.

[9] Q. R. Ali and S. Mahmoud Application of Optimal control and eigenvalue/eigenvector assignment for Jet engine control. I mech E proceedings C 16/87, 2011, 103-109. 
[10] A. Hamid, Modelling, Simulation and Control of Gas Turbines Using Artificial Neural Networks. University of Canterbury Christchurch, New Zealand,2014.

[11] M. H Ahmad, S.S Mohamed et al. Gas Turbine LQR, Integral Controllers and Optimal PID Tuning by Ant Colony Optimization Comparative Study. International Journal of Computer Science and Telecommunications 2013, Volume 4, Issue 1.

[12] A. T. Alouani Application Of Linear Multivariable Control Design For The Ge-21 Turbofan Jet Engine, Tennessee Technological University Cookeville, Tennessee USA, 1989.

[13] A. J. Ujam, Modeling Performance Characteristics of a Turbojet Engine, International Journal of Manufacturing, Material and Mechanical Engineering Research 2013,Vol.1, No. 1, pp.1-16.

[14] D.S. Naidu, Optimal Control Systems, CRC Press, Idaho State University,Pocatello, Idaho, USA, 2003.

[15] K. Ogata Modern, Control Engineering, Tom Robbins, New Jersey, USA, 1997, 3 Ed. 